\title{
RESEARCH BRIEF \\ The Prevalence of Tobacco Use at Federally Qualified Health Centers in the United States, 2013
}

\author{
Susan A. Flocke, $\mathrm{PhD}^{1,2,3,4}$; Richard Hoffman, $\mathrm{MD}^{5}$; Jan M. Eberth, MSPH, $\mathrm{PhD}^{6}$; \\ Hyunyong Park, $\mathrm{PhD}^{1,3}$; Genevieve Birkby, $\mathrm{MPH}^{1,2}$; Erika Trapl, $\mathrm{PhD}^{2,3,4}$; Steve Zeliadt, $\mathrm{PhD}^{7}$
}

\begin{abstract}
Suggested citation for this article: Flocke SA, Hoffman R, Eberth JM, Park H, Birkby G, Trapl E, et al. The Prevalence of Tobacco Use at Federally Qualified Health Centers in the United States, 2013. Prev Chronic Dis 2017;14:160510. DOI: https:// doi.org/10.5888/pcd14.160510.
\end{abstract}

\section{PEER REVIEWED}

\section{Abstract}

We explored tobacco use across federally qualified health centers (FQHCs) and compared data on state-level tobacco use between FQHC patients and the general population. We used data from the Uniform Data System (UDS) and the Behavioral Risk Factor Surveillance System (BRFSS) to generate estimates of 2013 prevalence of tobacco use among adults aged 18 years or older. According to UDS data, the overall prevalence of tobacco use was $25.8 \%$ in FQHCs compared with $20.6 \%$ in the general population represented by BRFSS data, an average of 5.2 percentage points (range, -4.9 to 20.9) higher among FQHCs. Among FQHCs, the burden of tobacco use and the opportunity for offering cessation assistance is substantial.

\section{Objective}

Tobacco use contributes to substantial illness and death in the United States (1). Although prevalence of tobacco use has declined during the past decade among some demographic groups, rates have remained steady and even increased among some socially and economically disadvantaged populations (2).

Federally qualified health centers (FQHCs), which provide comprehensive health services to economically disadvantaged populations in rural and urban communities in the United States, are required to collect data on tobacco use screening and tobacco cessation counseling rates as Uniform Data System (UDS) measures.
Understanding rates of tobacco use among $\mathrm{FQHC}$ clients can guide efforts to provide resources for tobacco cessation assistance where they are most needed (3-6).

Our study explores differences in tobacco use among FQHCs and compares state-level tobacco use between FQHC patients and the general population.

\section{Methods}

We used 2013 UDS FHQC data, which include quality-of-care indicators and patient demographics, to estimate tobacco use. We included only those FQHCs $(967$ of 1,202$)$ that obtain tobacco use data from an electronic health record (EHR). Our denominator was the number of adults ( $\geq 18 \mathrm{y}$ ) having 1 or more medical visits to a FQHC in 2013. The numerator was the number of adults using any form of tobacco including cigarettes, cigars, and smokeless tobacco, as documented during routine patient care.

We estimated the prevalence of adult tobacco users in each state's FQHC population by summing the total number of tobacco users across FQHCs and dividing by the total number of adult FQHC patients. We also estimated the prevalence of tobacco use for each FQHC and calculated the median and lowest and highest values for $\mathrm{FQHCs}$ in each state.

We then compared data on state-level estimates of FQHC tobacco use with data from the 2013 Behavioral Risk Factor Surveillance System (BRFSS), a random-digit-dial telephone survey that collects data on population-level prevalence of health risk behaviors among US adults aged 18 years or older. Three BRFSS items are used to indicate tobacco use: 1) "Have you smoked at least 100 cigarettes in your entire life?", 2) "Do you now smoke cigarettes every day, some days, or not at all?", and 3) "Do you currently use chewing tobacco, snuff, or snus every day, some days, or not at all?" Survey participants that responded yes to question 1 and every day or some days to either question 2 or question 3 were 
identified as tobacco users (7). We applied BRFSS sampling weights to estimate state-specific prevalence of tobacco use (8).

\section{Results}

In total, 1,202 FQHCs reported 2013 UDS data; 967 (80.4\%) collected EHR-based tobacco use data. In this subset, the nearly 9 million adult patients seen were similar to the US population in percentage female (58.7\%) and Hispanic (16.4\%). FQHC patients were less likely than the US population to be older than 65 years ( $7.3 \%$ vs $14.1 \%)$ and more likely to be black ( $20.5 \%$ vs $13.0 \%)$ or other race $(23.6 \%$ vs $8.6 \%)$. As expected, FQHC patients were more likely to be below the federal poverty level $(71.7 \%$ vs $14.8 \%)$ and uninsured $(34.8 \%$ vs $13.4 \%)$ or using government health insurance ( $50.8 \%$ vs $34.3 \%)$.

The overall proportion of tobacco use in FHQCs was $25.8 \%$, and median prevalence was $29.3 \%$, ranging from $0.4 \%$ to $94.4 \%$ across states (Table). BRFSS data from 2013 estimated US tobacco use at $20.6 \%$, ranging from $12.1 \%$ to $30.8 \%$ across states.

Except for 5 states, state-level prevalence of tobacco use in FQHCs was higher than the BRFSS national average (Table). FQHC tobacco use prevalence and differences between FQHC and state-level estimates are displayed in the Figure.
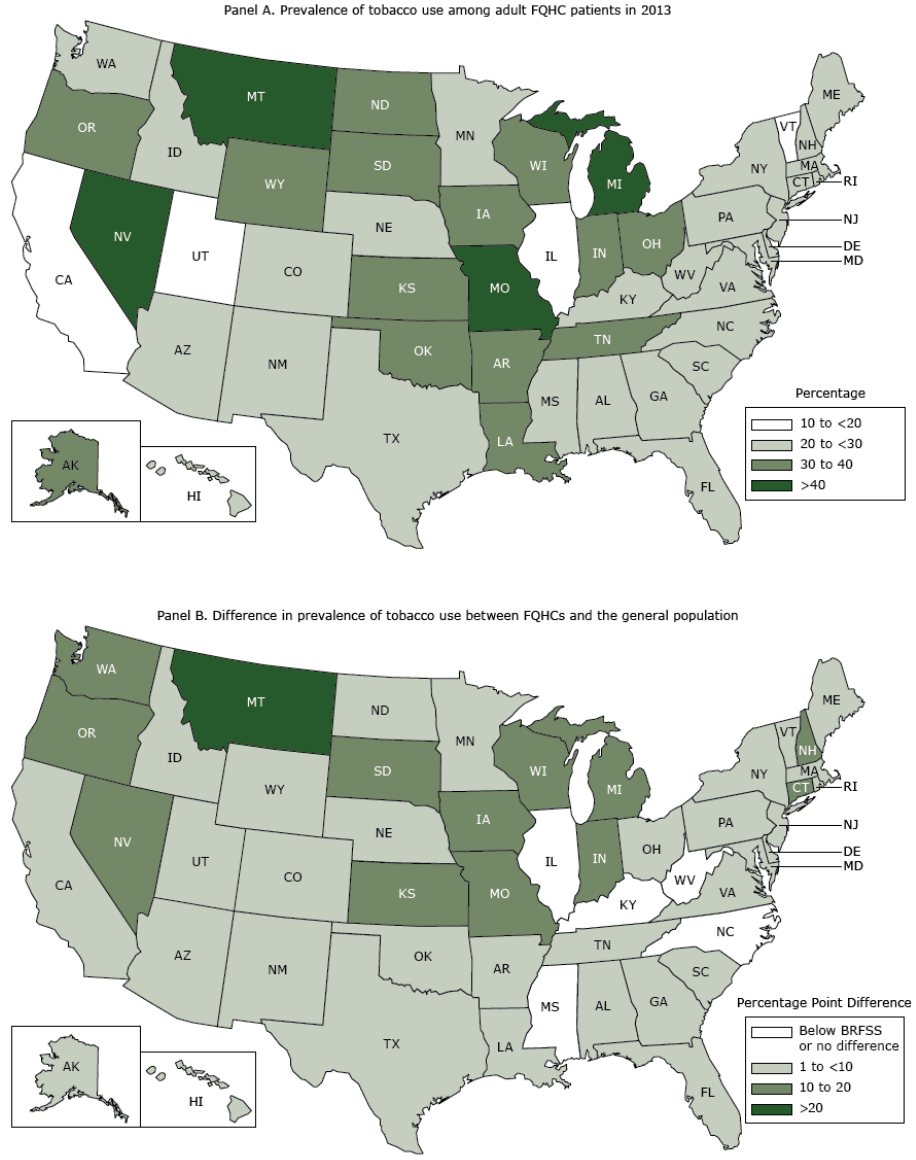

Figure. Federally qualified health center (FQHC) tobacco use prevalence and differences between $\mathrm{FQHC}$ and state-level estimates. Panel A shows the US prevalence of tobacco use among adult FQHC patients in 2013; panel B shows the differences in prevalence of tobacco use between FQHCs and the general population. Sources: Uniform Data System, 2013 (Panels A and B), and Behavioral Risk Factor Surveillance System, 2013 (Panel B).

Prevalence of tobacco use among individual FQHCs varied widely, even within states. Fifty-four percent of FQHCs had a tobacco prevalence greater than $30 \%$; $63 \mathrm{FQHCs}$ had tobacco use rates higher than $50 \%$.

\section{Discussion}

Our study is the first national assessment of the prevalence of tobacco use across FQHCs; previous reports focused on patient samples (9) or delivery of services among a subgroup of FQHCs (10). We found that in 2013 tobacco use among FQHC populations was considerably higher than for the general US population. Although the finding was not surprising, this report quantifies this difference for the first time. A second notable finding was the

\footnotetext{
The opinions expressed by authors contributing to this journal do not necessarily reflect the opinions of the U.S. Department of Health and Human Services, the Public Health Service, the Centers for Disease Control and Prevention, or the authors' affiliated institutions.
} 
wide range of tobacco use and high prevalence of tobacco use in some FQHCs, particularly in sites where more than half of adult patients use tobacco. Caring for patients in an environment where the prevalence of tobacco use is high poses substantial challenges and may require additional investment of resources to successfully offer tobacco cessation.

Assessing tobacco use rates is an important first step to targeting opportunities for intervention and quality improvement (4). Implementing clinical interventions and decision support tools to effectively act on EHR-documented tobacco use to support delivery of tobacco treatment has emerged as a national priority, especially in low-income settings (3-6).

This study has 2 main limitations. First, UDS data are collected for administrative purposes rather than for research; we cannot verify outlier values or dictate how variables are documented. Conversely, BRFSS data collection procedures are standardized but rely on self-report. In an effort to report the most robust data possible, we limited analyses to FQHCs that generated UDS quality elements using an EHR so that estimates are based on the patient population rather than a random sample of manually abstracted records. To ensure data reliability, we examined 2 prior years of UDS reporting for the top and bottom 5\% of FQHC tobacco use values; 2013 reporting prevalence was similar in all cases. Second, BRFSS is able to separate data on rates of combustible tobacco use and rates of smokeless tobacco use and in 2013 reported all tobacco use at $20.6 \%$, combustible at $19.4 \%$, and smokeless tobacco at $4 \%$ (7). However, UDS data combine all tobacco use (combustible and smokeless), limiting our ability to report tobacco use separately.

Recommendations by the US Preventive Services Task Force to offer annual lung cancer screening using low-dose computed tomography (LDCT) to long-term smokers older than 55 years will significantly affect FQHCs caring for older adults (11). Although the UDS cannot provide information on the number of individuals eligible for lung cancer screening (data on age and packyear history are lacking), given tobacco user prevalence, the effort to implement the LDCT scans in FQHCs is substantial and will require an evaluation of costs and approaches to integrating smoking cessation (12). Understanding more about how FQHC clinicians, staff, and patients are addressing tobacco use - and how they plan to address lung cancer screening - is essential for guiding efforts to implement systems- and evidence-based practices to promote tobacco cessation and offer lung cancer screening to eligible patients.

\section{Acknowledgments}

This article is a product of a Prevention Research Center supported by cooperative agreement no. 1U48DP005013 SIP-14-011 from the Centers for Disease Control and Prevention. The findings and conclusions in this report are those of the authors and do not necessarily represent the official position of the Centers for Disease Control and Prevention. This research was also supported by the Behavioral Measurement Shared Resource of the Case Comprehensive Cancer Center (no. P30CA043703). The authors thank the members of the Tobacco \& Lung Cancer Screening CPCRN Workgroup for their feedback and encouragement on this project and Nelson Oliver for assistance in the preparation of this manuscript.

\section{Author Information}

Corresponding Author: Susan A. Flocke, PhD, Associate Professor of Family Medicine and Community Health, Case Western Reserve University, 11000 Cedar Ave, Suite 402, Cleveland, $\mathrm{OH}$ 44106-7136. Telephone: 216-368-3887. Email: susan.flocke@case.edu.

Author Affiliations: ${ }^{1}$ Department of Family Medicine \& Community Health, Case Western Reserve University, Cleveland Ohio. ${ }^{2}$ Department of Epidemiology \& Biostatistics, Case Western Reserve University, Cleveland Ohio. ${ }^{3}$ Prevention Research Center for Healthy Neighborhoods, Case Western Reserve University, Cleveland Ohio. ${ }^{4}$ Case Comprehensive Cancer Center, Cleveland, Ohio. ${ }^{5}$ Division of General Internal Medicine, University of Iowa Carver College of Medicine, Iowa City, Iowa; Holden Comprehensive Cancer Center, University of Iowa, Iowa City, Iowa. ${ }^{6}$ South Carolina Rural Health Research Center, University of South Carolina, Columbia, South Carolina; Department of Epidemiology and Biostatistics, Arnold School of Public Health, University of South Carolina, Columbia, South Carolina; Cancer Prevention and Control Program, University of South Carolina, Columbia, South Carolina. ${ }^{7}$ University of Washington, School of Public Health, Seattle, Washington.

\section{References}

1. US Department of Health and Human Services. The health consequences of smoking - 50 years of progress: a report of the Surgeon General. Atlanta (GA): US Department of Health and Human Services, Centers for Disease Control and Prevention National Center for Chronic Disease Prevention and Health Promotion Health, Office on Smoking and Health; 2014.

\footnotetext{
The opinions expressed by authors contributing to this journal do not necessarily reflect the opinions of the U.S. Department of Health and Human Services, the Public Health Service, the Centers for Disease Control and Prevention, or the authors' affiliated institutions.
} 
2. Trinidad DR, Pérez-Stable EJ, White MM, Emery SL, Messer $\mathrm{K}$. A nationwide analysis of US racial/ethnic disparities in smoking behaviors, smoking cessation, and cessation-related factors. Am J Public Health 2011;101(4):699-706.

3. Kruse GR, Kelley JHK, Linder JA, Park ER, Rigotti NA. Implementation of an electronic health record-based care management system to improve tobacco treatment. J Gen Intern Med 2012;27(12):1690-6.

4. Clinical Practice Guideline Treating Tobacco Use and Dependence 2008 Update Panel, Liaisons, and Staff. A clinical practice guideline for treating tobacco use and dependence: 2008 update. A U.S. Public Health Service report. Am J Prev Med 2008;35(2):158-76.

5. Moody-Thomas S, Nasuti L, Yi Y, Celestin MD Jr, Horswell R, Land TG. Effect of systems change and use of electronic health records on quit rates among tobacco users in a public hospital system. Am J Public Health 2015;105(Suppl 2):e1-7.

6. Boyle R, Solberg L, Fiore M. Use of electronic health records to support smoking cessation. Cochrane Database Syst Rev 2014;(12):CD008743.

7. Nguyen K, Marshall L, Hu S, Neff L;Centers for Disease Control and Prevention (CDC). State-specific prevalence of current cigarette smoking and smokeless tobacco use among adults aged $\geq 18$ years - United States, 2011-2013. MMWR Morb Mortal Wkly Rep 2015;64(19):532-6.

8. The process of raking (iterative proportional fitting). Centers Disease Control and Prevention, Behavior Risk Factor Surveillance System fact sheet; 2011. http://health.mo.gov/ data/brfss/BRFSSweightingmethod.pdf. Accessed October 21, 2016.

9. Lebrun-Harris LA, Fiore MC, Tomoyasu N, Ngo-Metzger Q. Cigarette smoking, desire to quit, and tobacco-related counseling among patients at adult health centers. Am J Public Health 2015;105(1):180-8.

10. Silfen SL, Cha J, Wang JJ, Land TG, Shih SC. Patient characteristics associated with smoking cessation interventions and quit attempt rates across 10 community health centers with electronic health records. Am J Public Health 2015; 105(10):2143-9.

11. Moyer VA;US Preventive Services Task Force. Screening for lung cancer: U.S. Preventive Services Task Force recommendation statement. Ann Intern Med 2014; 160(5):330-8.

12. Piñeiro B, Simmons VN, Palmer AM, Correa JB, Brandon TH. Smoking cessation interventions within the context of LowDose Computed Tomography lung cancer screening: a systematic review. Lung Cancer 2016;98:91-8.

\footnotetext{
The opinions expressed by authors contributing to this journal do not necessarily reflect the opinions of the U.S. Department of Health and Human Services, the Public Health Service, the Centers for Disease Control and Prevention, or the authors' affiliated institutions.
}

4 Centers for Disease Control and Prevention • www.cdc.gov/pcd/issues/2017/16_0510.htm 


\section{Table}

Table. Prevalence of Tobacco Use Among Patients at Federally Qualified Health Centers ( $\mathrm{N}=967)$ and a Comparison With Population Prevalence, by State, United States, $2013^{a}$

\begin{tabular}{|c|c|c|c|c|c|c|c|}
\hline \multirow[b]{2}{*}{ State } & \multirow{2}{*}{$\begin{array}{l}\text { No. of } \\
\text { FQHCs }\end{array}$} & \multirow{2}{*}{$\begin{array}{l}\text { No. of Adult } \\
\text { FQHC } \\
\text { Patients }\end{array}$} & \multirow{2}{*}{$\begin{array}{c}\text { No. of FQHC } \\
\text { Patients That Use } \\
\text { Tobacco }\end{array}$} & \multicolumn{2}{|c|}{ FQHC Tobacco Use, \% } & \multirow{2}{*}{$\begin{array}{l}\text { Tobacco Use in } \\
\text { Population }{ }^{c}, \%\end{array}$} & \multirow{2}{*}{$\begin{array}{l}\text { Percentage Point } \\
\text { Difference }\end{array}$} \\
\hline & & & & Total $^{b}$ & Median (Range) & & \\
\hline All & 967 & $8,762,429$ & $2,258,335$ & 25.8 & $29.3(0.4-94.4)$ & 20.6 & 5.2 \\
\hline Montana & 16 & 53,930 & 24,611 & 45.6 & $40.2(19.1-77.0)$ & 24.7 & 20.9 \\
\hline Missouri & 18 & 154,137 & 62,359 & 40.5 & $40.7(17.2-60.3)$ & 25.8 & 14.7 \\
\hline Nevada & 3 & 26,250 & 10,565 & 40.2 & $33.0(23.7-48.9)$ & 21.5 & 18.7 \\
\hline Michigan & 25 & 237,769 & 95,341 & 40.1 & $40.9(18.7-63.9)$ & 23.4 & 16.7 \\
\hline Arkansas & 11 & 79,770 & 31,742 & 39.8 & $41.0(21.3-82.3)$ & 30.5 & 9.3 \\
\hline lowa & 11 & 58,802 & 23,342 & 39.7 & $35.5(18.6-50.4)$ & 22.9 & 16.8 \\
\hline South Dakota & 6 & 26,570 & 10,446 & 39.3 & $36.5(24.7-52.2)$ & 24.3 & 15.0 \\
\hline Kansas & 15 & 65,335 & 25,090 & 38.4 & $36.9(16.1-47.7)$ & 23.8 & 14.6 \\
\hline Indiana & 18 & 157,991 & 60,588 & 38.3 & $36.6(4.6-57.5)$ & 25.0 & 13.3 \\
\hline Wyoming & 3 & 8,585 & 3,088 & 36.0 & $36.9(21.8-53.0)$ & 26.8 & 9.2 \\
\hline Oklahoma & 17 & 76,648 & 27,089 & 35.3 & $37.6(14.8-58.4)$ & 28.2 & 7.1 \\
\hline Ohio & 30 & 209,899 & 72,597 & 34.6 & $38.4(12.3-72.8)$ & 26.0 & 8.6 \\
\hline North Dakota & 4 & 15,363 & 5,293 & 34.5 & $33.8(28.8-38.7)$ & 26.4 & 8.1 \\
\hline Wisconsin & 15 & 82,817 & 27,467 & 33.2 & $34.9(9.0-55.5)$ & 21.5 & 11.7 \\
\hline Tennessee & 24 & 195,473 & 64,589 & 33.0 & $31.9(9.1-60.1)$ & 27.6 & 5.4 \\
\hline Louisiana & 22 & 116,474 & 38,211 & 32.8 & $33.6(13.2-45.6)$ & 27.6 & 5.2 \\
\hline Alaska & 21 & 43,399 & 13,873 & 32.0 & $33.7(8.0-68.3)$ & 27.3 & 4.7 \\
\hline Oregon & 26 & 156,608 & 48,782 & 31.1 & $34.8(11.4-67.5)$ & 20.3 & 10.8 \\
\hline Connecticut & 9 & 73,298 & 21,852 & 29.8 & $29.7(15.2-38.9)$ & 16.7 & 13.1 \\
\hline Colorado & 12 & 155,570 & 46,297 & 29.8 & $31.7(19.3-46.7)$ & 20.5 & 9.3 \\
\hline West Virginia & 22 & 186,695 & 55,185 & 29.6 & $31.1(5.0-46.8)$ & 34.3 & -4.7 \\
\hline Kentucky & 16 & 126,970 & 37,361 & 29.4 & $33.8(12.7-66.1)$ & 30.8 & -1.4 \\
\hline Nebraska & 5 & 26,101 & 7,675 & 29.4 & $34.2(18.9-44.9)$ & 22.0 & 7.4 \\
\hline Washington & 21 & 377,869 & 109,186 & 28.9 & $30.2(9.4-43.1)$ & 18.3 & 10.6 \\
\hline New Mexico & 13 & 107,381 & 30,974 & 28.8 & $30.5(16.7-86.1)$ & 21.7 & 7.1 \\
\hline Maine & 15 & 106,992 & 30,777 & 28.8 & $29.8(9.6-50.5)$ & 21.5 & 7.3 \\
\hline South Carolina & 14 & 132,501 & 38,054 & 28.7 & $30.7(6.4-42.9)$ & 25.0 & 3.7 \\
\hline New Hampshire & 10 & 47,455 & 13,566 & 28.6 & $37.0(18.2-73.0)$ & 18.0 & 10.6 \\
\hline Idaho & 8 & 47,127 & 13,250 & 28.1 & $27.4(10.2-41.9)$ & 20.5 & 7.6 \\
\hline
\end{tabular}

Abbreviations: BRFSS, Behavioral Risk Factor Surveillance System; FQHC, federally qualified health center.

${ }^{a} 967 \mathrm{FQHCs}$, which use the electronic health record to report clinical data, were included in the analysis.

${ }^{b}$ Number of patients that use tobacco divided by the number of total patients.

${ }^{c}$ Data from 2013 BRFSS.

${ }^{\mathrm{d}}$ Difference in rate of tobacco use between patients at FQHCs and population. 
(continued)

Table. Prevalence of Tobacco Use Among Patients at Federally Qualified Health Centers ( $\mathrm{N}=967)$ and a Comparison With Population Prevalence, by State, United States, $2013^{\mathrm{a}}$

\begin{tabular}{|c|c|c|c|c|c|c|c|}
\hline \multirow[b]{2}{*}{ State } & \multirow[b]{2}{*}{$\begin{array}{l}\text { No. of } \\
\text { FQHCs }\end{array}$} & \multirow{2}{*}{$\begin{array}{l}\text { No. of Adult } \\
\text { FQHC } \\
\text { Patients }\end{array}$} & \multirow{2}{*}{$\begin{array}{c}\text { No. of FQHC } \\
\text { Patients That Use } \\
\text { Tobacco }\end{array}$} & \multicolumn{2}{|c|}{ FQHC Tobacco Use, \% } & \multirow[b]{2}{*}{$\begin{array}{l}\text { Tobacco Use in } \\
\text { Population }{ }^{c}, \%\end{array}$} & \multirow[b]{2}{*}{$\begin{array}{l}\text { Percentage Point } \\
\text { Difference }\end{array}$} \\
\hline & & & & Total $^{b}$ & Median (Range) & & \\
\hline Alabama & 11 & 155,704 & 41,945 & 26.9 & $30.6(10.6-54.0)$ & 25.8 & 1.1 \\
\hline Minnesota & 16 & 76,679 & 20,632 & 26.9 & $32.5(9.2-71.9)$ & 21.3 & 5.6 \\
\hline Maryland & 12 & 130,809 & 35,102 & 26.8 & $29.5(13.2-51.8)$ & 17.9 & 8.9 \\
\hline District of Columbia & 5 & 91,624 & 23,932 & 26.1 & $23.0(5.6-46.0)$ & 19.4 & 6.7 \\
\hline Mississippi & 18 & 146,677 & 37,948 & 25.9 & $26.0(11.7-48.7)$ & 30.8 & -4.9 \\
\hline Rhode Island & 6 & 49,169 & 12,640 & 25.7 & $30.5(17.1-40.6)$ & 18.3 & 7.4 \\
\hline Virginia & 23 & 166,179 & 41,099 & 24.7 & $29.9(2.2-58.9)$ & 21.6 & 3.1 \\
\hline Pennsylvania & 29 & 204,291 & 49,920 & 24.4 & $30.4(10.9-57.9)$ & 23.7 & 0.7 \\
\hline Hawaii & 12 & 52,740 & 12,843 & 24.4 & $21.3(11.0-33.5)$ & 14.4 & 10.0 \\
\hline Massachusetts & 30 & 348,859 & 81,403 & 23.3 & $26.6(5.4-85.5)$ & 17.4 & 5.9 \\
\hline North Carolina & 27 & 175,902 & 40,883 & 23.2 & $22.4(0.4-41.0)$ & 23.5 & -0.3 \\
\hline Georgia & 23 & 156,980 & 36,182 & 23.0 & $25.3(6.0-48.8)$ & 22.4 & 0.6 \\
\hline Delaware & 3 & 23,055 & 5,301 & 23.0 & $23.1(16.9-29.6)$ & 20.6 & 2.4 \\
\hline Florida & 38 & 385,604 & 88,308 & 22.9 & $26.0(1.5-74.7)$ & 18.5 & 4.4 \\
\hline Arizona & 14 & 208,388 & 47,314 & 22.7 & $24.9(13.3-70.9)$ & 18.3 & 4.4 \\
\hline New York & 51 & 759,384 & 165,743 & 21.8 & $29.3(3.0-94.4)$ & 17.9 & 3.9 \\
\hline New Jersey & 18 & 186,291 & 39,153 & 21.0 & $26.5(0.9-66.8)$ & 16.7 & 4.3 \\
\hline Texas & 61 & 516,650 & 104,219 & 20.2 & $21.2(3.7-64.5)$ & 18.8 & 1.4 \\
\hline Illinois & 28 & 378,107 & 73,535 & 19.4 & $22.9(4.5-53.0)$ & 19.7 & -0.3 \\
\hline Vermont & 7 & 74,147 & 14,218 & 19.2 & $22.7(8.4-41.5)$ & 18.9 & 0.3 \\
\hline California & 95 & $1,270,742$ & 228,999 & 18.0 & $20.2(4.3-78.8)$ & 13.6 & 4.4 \\
\hline Utah & 10 & 50,669 & 7,766 & 15.3 & $20.0(2.9-48.9)$ & 12.1 & 3.2 \\
\hline
\end{tabular}

Abbreviations: BRFSS, Behavioral Risk Factor Surveillance System; FQHC, federally qualified health center.

${ }^{a} 967 \mathrm{FQHCs}$, which use the electronic health record to report clinical data, were included in the analysis.

${ }^{\mathrm{b}}$ Number of patients that use tobacco divided by the number of total patients.

${ }^{c}$ Data from 2013 BRFSS.

${ }^{d}$ Difference in rate of tobacco use between patients at FQHCs and population.

The opinions expressed by authors contributing to this journal do not necessarily reflect the opinions of the U.S. Department of Health and Human Services, the Public Health Service, the Centers for Disease Control and Prevention, or the authors' affiliated institutions. 